\title{
ADSORÇÃO DE CORANTE CATIÔNICO UTILIZANDO RESÍDUO DA INDÚSTRIA CERVEJEIRA
}

\author{
B.D. ZORZI ${ }^{1}$, E.R. ECHEVARRIA ${ }^{1}$, E.G. OLIVEIRA ${ }^{2}$ e G.S. ROSA ${ }^{1}$ \\ ${ }^{1}$ Universidade Federal do Pampa, Engenharia Química \\ ${ }^{2}$ Universidade Federal do Rio Grande do Sul, Instituto de Ciência e Tecnologia de Alimentos \\ E-mail para contato: babizorzi20@gmail.com
}

\begin{abstract}
RESUMO - Este trabalho teve como objetivo avaliar a capacidade de utilização do bagaço de malte como adsorvente na remoção do corante azul de metileno em soluções aquosas. Para isso, foram realizados ensaios de adsorção com o bagaço do malte em duas condições: in natura e seco. A amostra seca foi obtida através de secagem em estufa a $40{ }^{\circ} \mathrm{C}$ por $24 \mathrm{~h}$. As amostras foram previamente moídas em moinho de hélices por 15 s. Para a obtenção das isotermas de adsorção foram preparadas as soluções do corante azul de metileno em 6 diferentes concentrações. Os resultados demonstraram que o bagaço de malte in natura e seco capacidade máxima de adsorção de $35,08 \mathrm{mg} . \mathrm{g}^{-1}$ e $12,80 \mathrm{mg}$. $\mathrm{g}^{-1}$ respectivamente,
\end{abstract}

\section{INTRODUÇÃO}

A busca por energias renováveis e limpas tem sido exigida atualmente devido a demanda energética e aos problemas ambientais causados pelo aumento da população e suas buscas tecnológicas.

O Brasil vem se destacando no que diz respeito a produção de etanol de cana-de açúcar e no aproveitamento de resíduos e efluentes de processos (BARBOSA, 2010). A utilização de biomassas se enquadra no conceito de desenvolvimento sustentável, além de reduzir custos e não agredir o meio ambiente (CORDEIRO, 2011). Resíduos sólidos da agroindústria, como o bagaço da cana de açúcar, mesocarpo de coco e serragens de madeira, estão disponíveis em grande quantidade e podem ser considerados adsorventes em potencial devido ao seu baixo custo por não receber nenhum tratamento prévio e por suas características físico-químicas (MATOS et al., 2013).

A definição de malte cervejeiro, segundo Brasil (1977), é o produto resultante da germinação forçada e controlada, sob condições especiais de umidade e temperatura, da cevada Hordeum sp. O bagaço do malte é um dos resíduos resultantes da produção cervejeira que de acordo com Ferrari (2008) provem da filtração do mosto após a caldeira de mistura e antes da fervura, é constituído basicamente de resto de cascas e polpa do malte além, dos grãos do adjunto (arroz, milho ou trigo).

A adsorção é uma operação unitária comumente utilizada para separar sólido-líquido, podendo se mostrar eficiente e de baixo custo, através do emprego de diferentes adsorventes (OLIVEIRA et al., 2014). Piffer et al. (2015) estudaram a dessorção de corante têxtil adsorvido em bagaço de malte a fim de avaliar a eficiência do processo e Zanette et al. (2015) relataram 
a adsorção do corante azul 5G utilizando o bagaço de malte, verificando a influência da velocidade de agitação no processo

O presente trabalho teve como objetivo avaliar a capacidade de utilização do bagaço de malte como adsorvente na remoção do corante azul de metileno em soluções aquosas.

\section{MATERIAIS E METODOS}

Para a realização deste trabalho foi utilizado bagaço de malte, cedido por uma micro cervejaria da cidade de Porto Alegre - RS. O material foi armazenado em embalagens plásticas e mantido sob congelamento à $-18^{\circ} \mathrm{C}$ até a realização dos experimentos. $\mathrm{O}$ descongelamento foi realizado sob refrigeração $\left(4^{\circ} \mathrm{C}\right)$ por $24 \mathrm{~h}$ antes do início das análises. As análises foram executadas no Laboratório de Engenharia Química da Universidade Federal do Pampa.

Foram realizados ensaios de adsorção com o bagaço do malte em duas condições: in natura e seco. A amostra seca foi obtida através de secagem em estufa a $40{ }^{\circ} \mathrm{C}$ por $24 \mathrm{~h}$. As amostras foram previamente moídas em moinho de hélices por $15 \mathrm{~s}$. Utilizou-se uma curva de calibração do corante azul de metileno para a determinação da concentração do corante remanescente após o processo de adsorção.

Para a obtenção das isotermas de equilíbrio foram preparadas as soluções do corante azul de metileno nas concentrações $25 \mathrm{mg}$. L $\mathrm{L}^{-1}, 50 \mathrm{mg}$. L $\mathrm{L}^{-1}, 75 \mathrm{mg} . \mathrm{L}^{-1}, 100 \mathrm{mg}$. L $\mathrm{L}^{-1}, 125 \mathrm{mg}$. L $\mathrm{L}^{-1} \mathrm{e}$ $150 \mathrm{mg}$. $\mathrm{L}^{-1}$. Adicionou-se $1 \mathrm{~g}$ de malte em cada erlenmeyer seguido de $50 \mathrm{~mL}$ da solução do corante, então levou-se para a mesa agitadora onde permaneceu em agitação a 160 rpm durante $1 \mathrm{~h}$ (Figura 1). Ao final do processo as amostras foram centrifugadas a $3000 \mathrm{rpm}$ por $10 \mathrm{~min} \mathrm{e}$ então foram realizadas as leituras de absorbância em espectrofotômetro com comprimento de onda $\lambda=664 \mathrm{~nm}$.

Figura 1 - Processo de adsorção do corante azul de metileno

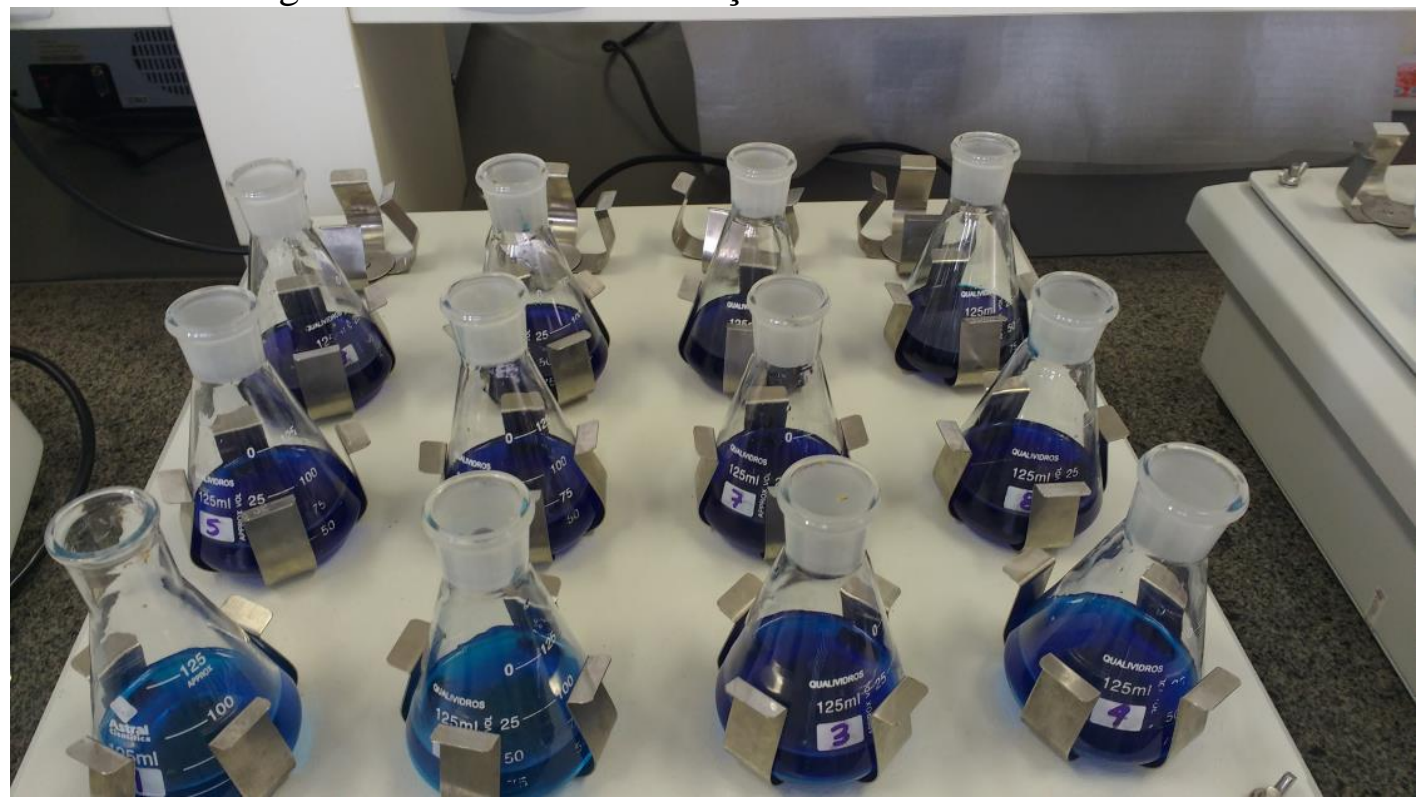




\section{C\&BEO IEO

As amostras foram quantificadas quanto as concentrações de corante ainda presentes na fase líquida (equilíbrio) utilizando a Equação 1.

$q_{e q}=\frac{v\left(C_{0}-C_{e q}\right)}{m}$

em que $C_{0}$ é a concentração inicial da solução, $C$ eq é a concentração final da solução, $V$ é o volume da solução e $m$ é a massa seca do adsorvente.

Para a obtenção da capacidade máxima de adsorção foi utilizada a equação de Langmuir na sua forma linearizada representada na Equação 2.

$q_{e q}=\frac{q_{m} \cdot k \cdot C_{e q}}{1+k \cdot C_{e q}}$

em que $q_{m}$ é a capacidade máxima de adsorção do corante por unidade de massa, $k$ é constante de adsorção e $C_{e q}$ é a concentração de corante na fase líquida.

\section{RESULTADOS E DISCUSSÃO}

Na Figura 2 pode-se observar o resultado visual dos ensaios, em que é possível observar que ocorreu a adsorção do corante, sendo essa mais pronunciada para as amostras secas em estufa a $40{ }^{\circ} \mathrm{C}$.

Figura 2: Resultado dos ensaios de adsorção para amostras in natura e seca.
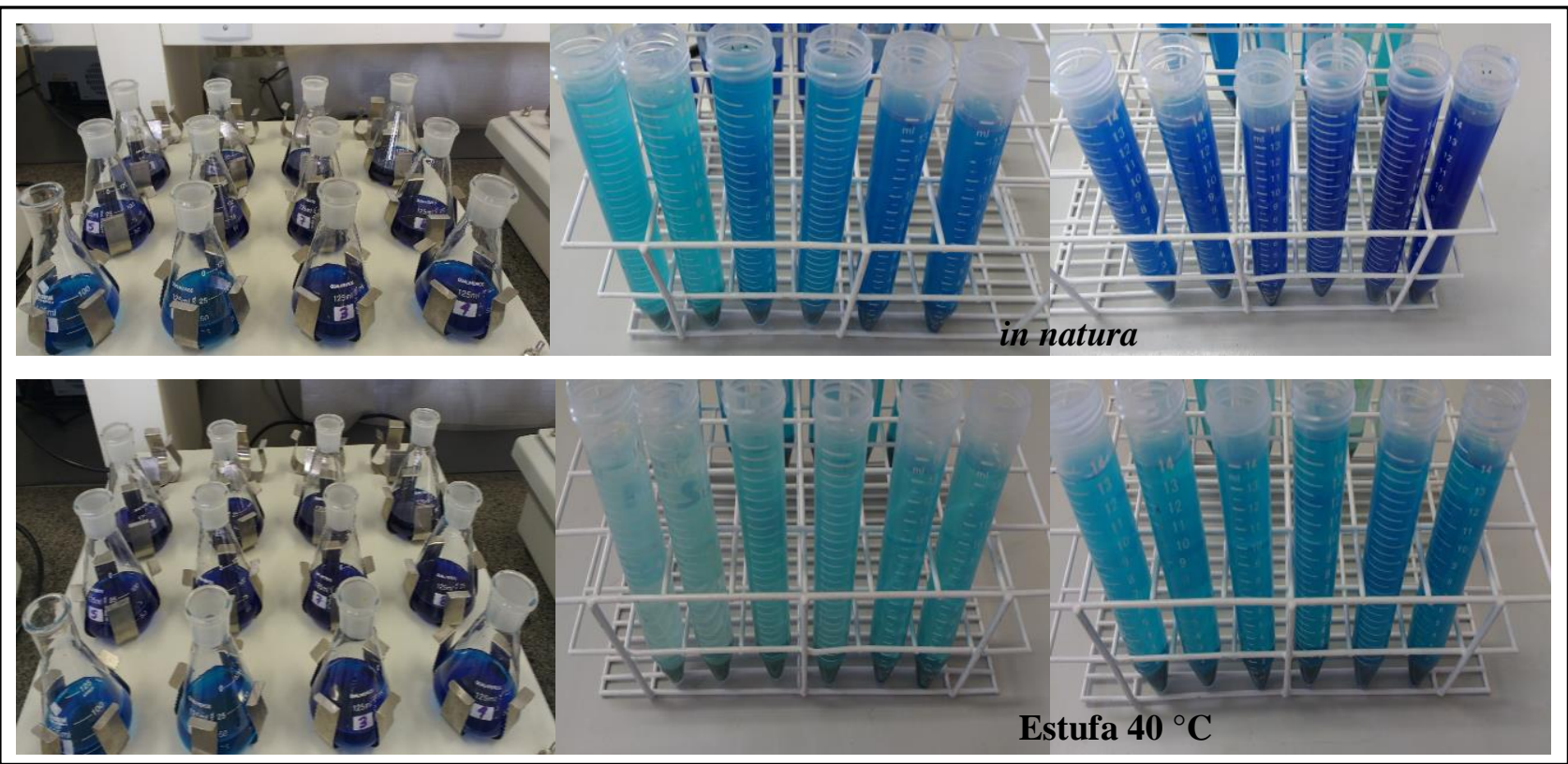

A Figura 3 apresenta os percentuais de remoção do corante nas duas condições estudadas.

Figura 3: Percentual de remoção do corante azul de metileno. 


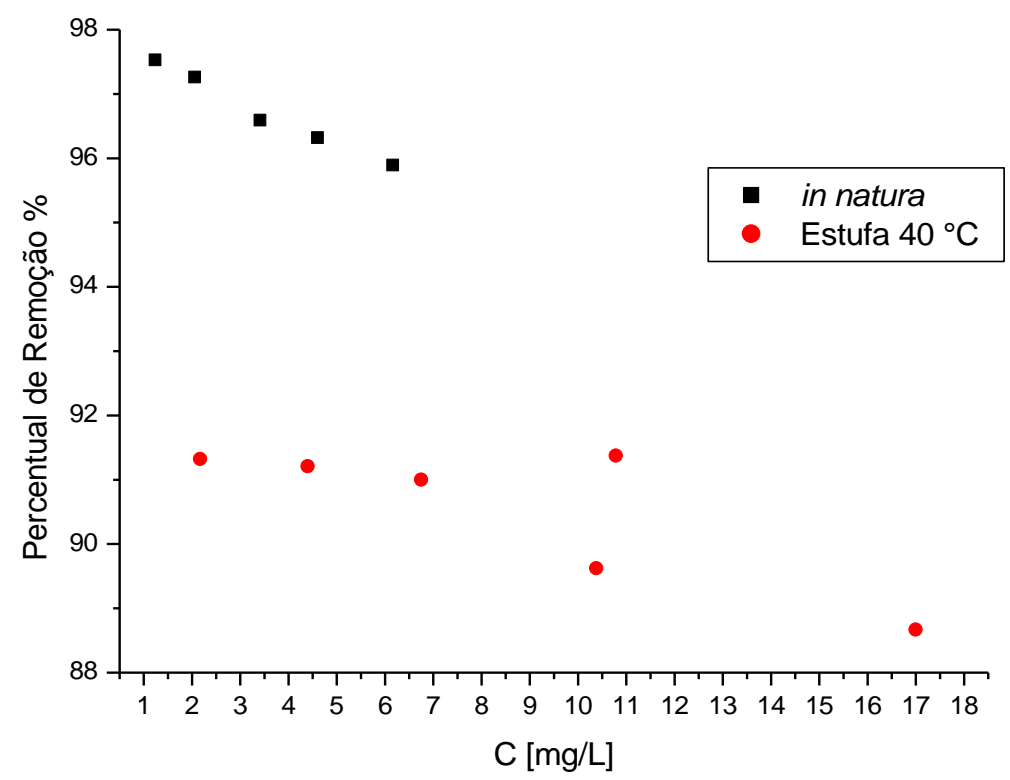

De acordo com a Figura 3 o maior percentual de remoção foi de 96,60 \% para a amostra de bagaço de malte in natura, já para as amostras secas o maior percentual de remoção foi de 91,37\%, sendo esses resultados considerados próximos.

Para melhor avaliar a capacidade de utilização do bagaço de malte como adsorvente obteve-se os parâmetros da equação de Langmuir, apresentados na abela 1.

Tabela 1 - Parâmetros das Isotermas de adsorção.

\begin{tabular}{cccc}
\hline & $\mathrm{q}_{\mathrm{m}}\left[\mathrm{mg} \cdot \mathrm{g}^{-1}\right]$ & $\mathrm{K}$ & $\mathrm{R}^{2}$ \\
\hline $\begin{array}{c}\text { Estufa } \\
40^{\circ} \mathrm{C}\end{array}$ & 35,0 & 0,015 & 0,99 \\
$\begin{array}{c}\text { in } \\
\text { natura }\end{array}$ & 12,80 & 0,078 & 0,997 \\
\hline
\end{tabular}

Pode-se observar que a capacidade máxima de adsorção foi de 35,08 mg. $\mathrm{g}^{-1}$ e 12,80 mg. $\mathrm{g}^{-1}$ para as amostras secas em estufa e in natura, respectivamente, o que indica que a secagem potencializa a utilização do bagaço como adsorvente. Os valoresforam inferiores aos encontrados por Gonçalves et al. (2016) que foram de 103,01 mg. $\mathrm{g}^{-1}$ para amostras secas em secador de túnel com escoamento paralelo de ar com velocidade de $2 \mathrm{~m} / \mathrm{s}$ e temperatura de 40 ${ }^{\circ} \mathrm{C}$. Zanette et al. (2009 b) citam que para a amostra seca na temperatura de $40{ }^{\circ} \mathrm{C}$ a adsorção do corante azul $5 \mathrm{Gcom}$ bagaço de malte apresentou qm 40,20 mg. g-1

\section{CONCLUSÕES}


Com a realização deste trabalho pode-se perceber que o bagaço do malte é uma alternativa para adsorção do corante azul de metileno. Através das isotermas de adsorção foi possível identificar que a condição em que a amostra foi seca em estufa a $40{ }^{\circ} \mathrm{C}$ apresentou maior capacidade máxima de adsorção $\left(\mathrm{q}_{\mathrm{m}}\right)$ obtendo-se um valor de $35,08 \mathrm{mg}$.g-1,enquanto que a amostra in natura apresentou $12,80 \mathrm{mg}$. $\mathrm{g}^{-1}$

\section{NOMENCLATURA}

$\begin{array}{lcc}C_{e q} & \text { Concentração de corante na fase líquida } & {\left[\mathrm{mg} . \mathrm{L}^{-1}\right]} \\ C_{f} & \text { Concentração inicial de corante na solução } & {\left[\mathrm{mg} . \mathrm{L}^{-1}\right]} \\ C_{o} & \text { Concentração inicial de corante na solução } & {\left[\mathrm{mg} . \mathrm{L}^{-1}\right]} \\ K & \text { Constante de adsorção } & {[-]} \\ M & \text { Massa da biomassa seca } & {[\mathrm{g}]} \\ q_{e} & \text { Capacidade de adsorção de equilíbrio } & {\left[\mathrm{mg} \cdot \mathrm{g}^{-1}\right]} \\ q_{m} & \text { Capacidade máxima de adsorção } & {\left[\mathrm{mg} \cdot \mathrm{g}^{-1}\right]} \\ \mathrm{R} & \text { Coeficiente de correlação } & {[\mathrm{kg}]} \\ \mathrm{V} & \text { Volume da solução } & {[\mathrm{ml}]} \\ \lambda & \text { Comprimento de onda } & {[\mathrm{nm}]}\end{array}$

\section{REFERENCIAS}

BARBOSA, R. M. Contribuição do Mercado de Carbono para a Viabilidade de Projetos de Eficiência Energética Térmica e de Troca de Combustíveis em Cervejarias. Dissertação de Mestrado. Universidade de São Paulo, 2010.

BRASIL. Ministério da Agricultura, Pecuária e Abastecimento. Portaria n ${ }^{\circ} 166$ de 12 de abril de 1977. Padronização, classificação e comercialização do Malte cervejeiro ou Cevada malteada para fins cervejeiros.

CORDEIRO, L. G. Caracterização e Viabilidade Econômica do Bagaço de Malte Oriundo de Cervejarias para Fins Energéticos. Dissertação de Mestrado. Universidade Federal da Paraíba, 2011.

FERRARI, V. O Mercado de Cervejas no Brasil. Dissertação de Mestrado. Universidade Católica doRio Grande do Sul, 2008.

FOUST, A. S.; WENZEL, L. A.; CLUMP, C. W.; MAUS, L.; ANDERSEN, L. B. Princípios das Operações Unitárias. Rio de Janeiro, Guanabara Dois, 1982. 670 p 
GEANKOPLIS, C. J. Procesos de transporte y operaciones unitarias. $3^{\circ}$ Edição, México: CECSA, 1998 .

GONÇALVES, C. ; ECHEVARRIA, E. R. ; ROSA, G.S. ;OLIVEIRA, E.G.; Biossorção de corante catiônico utilizando o bagaço de malte. Anais do XXI Congresso Brasileiro de Engenharia Química, Fortaleza, 2016

LOPES, C.R.; QUEIROZ, A. M.; SILVA, K. C.; MENDES, E. C. S.; SILVÉRIO, B.C.; FERREIRA,M. M. P.; Estudo Cinético de Desidratação e Caracterização do Bagaço de Malte Resíduo da Indústria, p. 2697-2702. In: Anais do XI Congresso Brasileiro de Engenharia Química em Iniciação Científica. São Paulo: Blucher, 2015.

PIFFER, H. H.; JUCHEN, P. T.; VEIT, M. T.; FAGUNDES-KLEN, M. R.; PALÁCIO, S. M.; GONÇALVES, G. C. Estudo da Dessorção do Corante Têxtil Reativo Azul 5g Adsorvido em Bagaço de Malte. In: Anais do XI Congresso Brasileiro de Engenharia Química em Iniciação Científica. São Paulo: Blucher, 2015.

ZANETTE, J. C.; PIFFER, H. H.; VEIT, M. T. Biossorção do Corante Têxtil Azul 5G Utilizando o Bagaço de Malte. In: Anais do I Encontro Anual de Iniciação Científica, Tecnológica e Inovação. Santa Catarina, 2015. 